\title{
Meiose e viabilidade polínica em linhagens avançadas de pimenta
}

\author{
Marisa T Pozzobon'; Karina RR de Souza²; Sabrina IC de Carvalho²; Francisco JB Reifschneider ${ }^{2}$ \\ ${ }^{1}$ Embrapa Cenargen, C. Postal 2372, 70770-900 Brasília-DF, marisa@cenargen.embrapa.br; ${ }^{2}$ Embrapa Hortaliças, C. Postal 218, 70351- \\ 970 Brasília-DF, karinareis@cnph.embrapa.br, sabrina@cnph.embrapa.br, fjbr@cnph.embrapa.br
}

\section{RESUMO}

Doze linhagens de pimenta, incluindo exemplares do tipo Jalapeño (CNPH 2862, CNPH 2864), Dedo-de-Moça (CNPH 1397, CNPH 0039, CNPH 0053), Cambuci (CNPH 0283), Peixe-Boi (CNPH 0434), Falsa Cumari (CNPH 3761), Bode Vermelha (CNPH 3773), Biquinho Doce (CNPH 3870), Tabasco (CNPH 3000) e Malagueta (CNPH 2869) tiveram o comportamento meiótico e a estimativa da viabilidade do pólen analisados, com o objetivo de indicar materiais potencialmente férteis para o programa de melhoramento de Capsicum da Embrapa. A análise convencional, por coloração, revelou um comportamento relativamente normal, durante a microsporogênese, para a maioria das linhagens, com índice meiótico (IM) e percentual médio de viabilidade polínica acima de $90 \%$. As principais anormalidades observadas foram aderências cromossômicas, cromossomos não orientados, retardatários, pontes, micronúcleos, micrócitos e citomixia. Três linhagens, CNPH 0283, CNPH 3000 e CNPH 3773 mostraram menor percentual de pólens viáveis, respectivamente 77, 66 e 58\%. Somente para CNPH 0283 a baixa fertilidade do pólen esteve associada à maior frequência de irregularidades e, consequentemente, ao baixo IM (77\%). Os resultados do presente trabalho confirmam a importância da análise citológica como ferramenta auxiliar na seleção de linhagens meioticamente estáveis e potencialmente férteis o que possibilita o planejamento de programas de produção de sementes das cultivares em vias de lançamento.

Palavras-chave: Capsicum, citogenética, comportamento meiótico, estabilidade genética.

\section{ABSTRACT}

\section{Meiosis and pollen viability in advanced lines of pepper}

Twelve lines of pepper, from different groups \{Jalapeño (CNPH 2862, CNPH 2864), Dedo-de-Moça (CNPH 1397, CNPH 0039, CNPH 0053), Cambuci (CNPH 0283), Peixe-Boi (CNPH 0434), Falsa Cumari (CNPH 3761), Bode Vermelha (CNPH 3773), Biquinho Doce (CNPH 3870), Tabasco (CNPH 3000) and Malagueta (CNPH 2869) had their meiotic behavior and the estimation of pollen viability analyzed with the aim of indicating potentially fertile material for the Capsicum breeding program. Conventional analysis by staining revealed a slightly irregular behavior during microsporogenesis for the majority of lines: the meiotic index (MI) and pollen viability were over $90 \%$, therefore considered meiotically stable. The main abnormalities observed were chromosome stickiness, unoriented chromosomes, laggards, bridges, micronuclei, microcytes and cytomixis. Three lines (CNPH 0283, CNPH 3000 and CNPH 3773) showed lower pollen viability, 77, 66 and $58 \%$ respectively. The lower pollen viability in CNPH 0283 was associated with higher frequency of irregularities and consequently the low MI (77\%). The findings of the present manuscript confirm the importance of the cytological analyzes as a useful tool in selecting of lines meiotically stable and potentially fertile enabling a better planning of seed production of promising cultivars.

Keywords: Capsicum, cytogenetics, meiotic behavior, genetic stability.

(Recebido para publicação em 21 de fevereiro de 2010; aceito em 5 de maio de 2011)

(Received on February 21, 2010; accepted on May 5, 2011)

$\mathrm{O}$ Brasil é considerado centro de diversidade para algumas espécies de Capsicum, pois em seu território encontram-se espécies de todos os níveis de domesticação (domesticadas, semidomesticadas e silvestres). Dentre as pimentas, de acordo com Ribeiro \& Reifschneider (2008), são cultivados diferentes tipos varietais pertencentes às quatro espécies domesticadas (Capsicum annuum L. var. annuum, C. baccatum L. var. pendulum (Willd.) Eshbaugh, $C$. chinense Jacq. e $C$. frutescens L.) e a pelo menos tres espécies semidomesticadas (C. annuиm var. glabriusculum (Dunal) Eshbaugh \& Smith, C. baccatum var. praetermissum (Heiser \& Smith) Hunziker e $C$. baccatum L. var. baccatum). A variabilidade existente pode ser observada nos frutos, que apresentam variações de tamanhos, cores, sabores e pungência, que é uma característica exclusiva deste gênero (Carvalho \& Bianchetti, 2008).

O cultivo de pimentas ocorre praticamente em todas as regiões brasileiras e é um dos melhores exemplos de agricultura familiar e de integração pequeno agricultor-agroindústria. Um dos problemas que mais afeta a produtividade da cultura é a suscetibilidade às diferentes doenças (Reifschneider, 2000). Nos últimos vinte e oito anos, o programa de melhoramento de Capsicum realizado na Embrapa Hortaliças, tem sido direcionado, principalmente, para resistência múltipla a doenças, tendo como resultado a disponiblização de cultivares, híbridos e uma série de linhagens que vêm sendo utilizadas tanto no Brasil quanto no exterior (Ribeiro \& Reifschneider, 2008).

Para assegurar o sucesso do uso desses indivíduos superiores selecionados e, principalmente, produção de novas cultivares por meio da recombinação de caracteres pela hibridação controlada, é importante que o pólen a ser utilizado tenha boa viabilidade. A elevada instabilidade meiótica, associada às anormalidades genéticas e/ou aberrações cromossômicas, que resultam na formação de plantas atípicas, macho-estéreis ou incapazes de formação de grãos de 
pólen, podem prejudicar a obtenção dos padrões mínimos exigidos para a produção de sementes assim como afetar a polinização. Estudos descritos por Bione et al. (2000), têm mostrado que o declínio na produção de sementes está correlacionado a irregularidades meióticas.

Considerando esses aspectos, neste trabalho avaliou-se a estabilidade meiótica e a viabilidade do pólen de doze linhagens de pimenta, com o objetivo de indicar genótipos potencialmente férteis ao programa de melhoramento de Capsicum da Embrapa.

\section{MATERIAL E MÉTODOS}

As análises citológicas foram realizadas no Laboratório de Citogenética da Embrapa Recursos Genéticos e Biotecnologia, Brasília-DF.

Doze linhagens do programa de melhoramento de Capsicum da Embrapa Hortaliças, Brasília-DF, de diferentes espécies e tipos de pimentas, selecionados para resistência a doenças e características de interesse agronômico, foram analisadas: Capsicum. annuиm L., tipo Jalapeño (CNPH 2862, CNPH 2864); C. baccatum L. var. pendulum (Willd.) Eshbaugh, tipo Dedo-de-Moça (CNPH 1397, CNPH 0039, CNPH 0053); C.baccatum L., tipo Cambuci (CNPH 0283); C. chinense Jacq., tipo Peixe-Boi (CNPH 0434); C. chinense Jacq., tipo Falsa Cumari (Cumari-do-Pará) (CNPH 3761); C. chinense Jacq., tipo Bode Vermelha (CNPH 3773); $C$. chinense Jacq., tipo Biquinho Doce (CNPH 3870); C. frutescens L., tipo Tabasco (CNPH 3000) e C. frutescens L., tipo Malagueta (CNPH 2869).

Para a análise meiótica e viabilidade dos grãos de pólen, foram utilizados protocolos convencionais de citogenética descritos por Guerra \& Souza (2002) e Singh (2002). Para cada linhagem foram coletados, aleatoriamente, botões florais, em diferentes fases de desenvolvimento, de plantas mantidas em casa de vegetação na Embrapa Hortaliças. Esses foram fixados em etanol-ácido acético (3:1) por $24 \mathrm{~h}$ e estocados em álcool a $70 \%$, em refrigerador, até a análise. $\mathrm{Na}$ preparação das lâminas, as anteras foram maceradas e coradas em carmim propiônico a $2 \%$. Para acompanhar o processo meiótico, todas as células disponíveis, nas diferentes fases da divisão meiótica, foram examinadas (Tabela 1).

O índice meiótico (IM) foi estimado de acordo com o proposto por Love (1949). Tétrades com quatro células de tamanho igual foram consideradas normais, e qualquer desvio como anormal.

A viabilidade do pólen foi estimada, para cada linhagem, a partir da análise de pelo menos 1.000 grãos de pólen/ flor, corados com orceína acética a $2 \%$. Grãos com tamanho visivelmente normal, protoplasma corado e com a exina intacta foram considerados como viáveis e aqueles vazios e, ou mal formados, como inviáveis.

\section{RESULTADOS E DISCUSSÃO}

Para todas as linhagens avaliadas (Tabela 1), tanto na meiose I quanto na meiose II, o percentual de células normais foi predominante. $\mathrm{O}$ pareamento cromossômico, em diacinese (Figura 1A) e metáfase I, foi regular para a maioria das linhagens. Cromossomos fora da placa equatorial, assim como aderências dos cromossomos foram observadas, principalmente para a linhagem CNPH 0283, o que dificultou a interpretação das associações cromossômicas. Aderências em metáfase I e outras fases podem ser causadas por fatores genéticos ou ambientais e têm sido descritas como uma das causas do decréscimo da viabilidade polínica (Pagliarini et al., 2000; Taschetto et al., 2003).

Durante a segregação cromossômica foram observadas irregularidades, como: cromossomos retardatários $\mathrm{e}$ pontes em anáfase e telófase I e cromossomos fora da placa equatorial em metáfase II. Em uma única célula, em anáfase II, foi observada ponte. Micronúcleos, retardatários, pontes, formação de dois, três, cinco núcleos em vez de quatro e núcleos de diferentes tamanhos, além de aderências, foram observados em telófase II (Figura 1D).

A porcentagem de tétrades normais, expressa por meio dos valores do índice meiótico (Tabela 1), foi considerada alta, exceção para a linhagem $\mathrm{CNPH}$
0283 com 79,53\%. Tétrades com células de tamanho desigual, presença de micronúcleos nos micrósporos, díades (Figura 1B), tríades e políades com ou sem a presença de micrócitos e, ou micronúcleos, também foram observadas.

As díades observadas nas linhagens CNPH 2864, CNPH 0053, CNPH 0283 e CNPH 3773, bem como as tríades nas linhagens CNPH 2862, CNPH 0039, CNPH 0053, CNPH 0283 e CNPH 3773 , possivelmente foram originadas de núcleos de restituição observados entre a pró-metáfase e anáfase II, semelhante ao que foi relatado por Pozzobon \& Schifino-Wittmann (2006) para espécies de Capsicum. A presença de micrócitos, provavelmente eliminação de cromossomos que aparecem como micronúcleos em fases anteriores da meiose, são relatados para Capsicum (Shopova, 1966; Pozzobon \& Schifino-Wittmann, 2006).

Considerando-se o índice meiótico, um dado complementar na análise meiótica e um indicador de regularidade (Love, 1949), pode-se afirmar que a maioria das linhagens analisadas é meioticamente estável com produção de gametas masculinos balanceados. Esse é um parâmetro simples, mas muito utilizado em estudos do comportamento meiótico de plantas, como Baccharis trimera, da família Asteraceae (Auler et al., 2006), espécies forrageiras de Adesmia (Tedesco, 2000) e Macroptilium (Garcia \& Battistin, 2002), espécies de Capsicum (Pozzobon \& Schifino-Wittmann, 2006), entre outros.

Outras irregularidades como citomixia (Figura 1C) e células anucleadas foram observadas, confirmando dados anteriores para Capsicum (Lakshmi et al., 1989; Pozzobon \& Schifino-Wittmann, 2006). Esse fenômeno é citado para um grande número de plantas (Pagliarini, 2000; Kumar \& Singhal, 2008; Sheidai et al., 2008; Risso-Pascotto et al., 2009; Kumar et al., 2010). A migração de cromatina pode ser tanto parcial como completa, o que resulta na formação de células anucleadas, hipo ou hiperplóide parcial, comprometendo a fertilidade do pólen (Singhal \& Kumar, 2008; Risso-Pascotto et al., 2009). Podem-se associar à citomixia demais distúrbios como aderências na metáfase I, disjunção 
Tabela 1. Comportamento meiótico, índice meiótico (IM) e viabilidade dos grãos de pólen em linhagens de pimentas (meiotic behavior, meiotic index (IM) and pollen grains viability in lines of pepper). Brasília, Embrapa Recursos Genéticos e Biotecnologia, 2009.

\begin{tabular}{|c|c|c|c|c|c|c|c|c|}
\hline Linhagem & Espécie & $\begin{array}{l}\mathrm{N}^{0} \mathrm{de} \\
\text { células }\end{array}$ & $\begin{array}{c}\text { Anáfase/ } \\
\text { telófase I } \\
\text { (\% normal) }\end{array}$ & $\begin{array}{l}\mathrm{N}^{0} \text { de } \\
\text { células }\end{array}$ & $\begin{array}{l}\text { Anáfase/te- } \\
\text { lófase II (\% } \\
\text { normal) }\end{array}$ & $\begin{array}{c}\mathrm{N}^{0} \text { de } \\
\text { tetrades* }\end{array}$ & $\begin{array}{l}\text { IM } \\
(\%)\end{array}$ & $\begin{array}{c}\text { Viabilidade } \\
\text { pólen (\%) }\end{array}$ \\
\hline CNPH 2862 & C. annuum & 311 & 79,74 & - & - & 2077 & 97,30 & 90,20 \\
\hline CNPH 2864 & C. annuиm & 10 & 100,00 & 487 & 90,35 & 861 & 92,33 & 96,60 \\
\hline CNPH 1397 & $\begin{array}{l}\text { C. baccatum } \\
\text { var. pendulum }\end{array}$ & 99 & 93,94 & 1417 & 91,60 & 447 & 100 & - \\
\hline CNPH 0039 & $\begin{array}{l}\text { C. baccatum } \\
\text { var. pendulum }\end{array}$ & 138 & 92,03 & 549 & 75,77 & 231 & 91,77 & - \\
\hline CNPH 0053 & $\begin{array}{l}\text { C. baccatum } \\
\text { var. pendulum }\end{array}$ & 333 & 81,08 & 4843 & 98,22 & 5576 & 98,18 & 96,35 \\
\hline CNPH 0283 & C. baccatum & 153 & 67,32 & 614 & 84,20 & 1212 & 79,53 & 76,73 \\
\hline CNPH 0434 & C. chinense & 75 & 94,66 & 2366 & 90,40 & 794 & 94,33 & 95,85 \\
\hline CNPH 3761 & C. chinense & - & - & 664 & 97,43 & 754 & 97,08 & 96,08 \\
\hline CNPH 3773 & C. chinense & 154 & 96,75 & 1885 & 96,07 & 1281 & 90,86 & 57,80 \\
\hline CNPH 3870 & C. chinense & 693 & 100,00 & 1160 & 98,53 & 1129 & 98,76 & 94,50 \\
\hline CNPH 3000 & C. frutescens & 708 & 94,49 & 1266 & 97,79 & 3708 & 98,79 & 66,08 \\
\hline CNPH 2869 & C. frutescens & 57 & 100,00 & 1063 & 98,40 & 2603 & 99,31 & 81,60 \\
\hline
\end{tabular}

$\mathrm{N}^{\circ}$ de células $=$ número de células analisadas (number of cells analyzed); *Número total de tétrades analisadas (total number of tetrads analyzed).

tardia na anáfase I, cromatina picnótica, pontes e cromossomos retardatários em anáfase e telófase (Singhal et al., 2008; Kumar et al., 2010).

A viabilidade polínica, estimada para dez linhagens, é mostrada na Tabela 1 e ilustrada na Figura 1 (E e F). Elevada porcentagem $(>81 \%$ ) de grãos de pólen corados foi registrada para a maioria sugerindo que, provavelmente, as irregularidades observadas na meiose não foram significativas em termos da fertilidade.

Destacam-se pela baixa porcentagem de grãos de pólen viáveis as linhagens CNPH 0283 (C. baccatum), CNPH 3773 (C. chinense) e CNPH 3000 ( $C$. frutescens) com 77, 58 e $66 \%$, respectivamente. Destas, a linhagem CNPH 0283 expressou a maior porcentagem de irregularidades, durante o processo de divisão celular, em todas as fases da meiose (Tabela 1). Foram observados grãos de pólen com tamanho maior do que o normal, possivelmente derivados das várias díades e tríades encontradas. A presença de grãos de pólen gigantes é relatada em Capsicum (Shopova, 1996; Pozzobon \& Schifino-Wittmann, 2006), indicando, eventualmente, gametas não reduzidos (Ramsey \& Schemske, 1998) ou, pelo menos gametas com número de cromossomos diferentes. Gametas com cromossomos desbalanceados ou anucleados, como grãos de pólen com citoplasma retraído são citados como resultado de falhas no comportamento meiótico (Zanotto et al., 2009).

Para as linhagens CNPH 3773 e CNPH 3000, houve uma proporção relativamente alta de grãos de pólen mal corados e vazios, em relação à regularidade observada nas diferentes fases da meiose. Resultado semelhante foi observado para uma população de Vriesea gigantea em que apesar de ter uma meiose regular apresentou baixa viabilidade polínica. Depressão endogâmica, além de causas não genéticas, incluindo estágio do pólen e fatores físicos como temperatura e umidade são citadas como fatores que podem afetar a viabilidade do pólen (Palma-Silva et al., 2008). De acordo com Shopova (1966) a autofertilização pode ser considerada como causa de distúrbios observados na meiose em C. annuum, C. frutescens e C. pubescens, mas esses não teriam, necessariamente, influência na fertilidade das plantas analisadas. Vírus e outros patógenos podem, também, alterar os processos citológicos em Capsicum, ocasionando irregularidades meióticas (Mircova \& Sotirova, 1995), assim como o aumento na temperatura pode afetar a viabilidade e germinação do pólen (Raja Reddy \& Kakani, 2007; Kafizadeh et al., 2008). Anormalidades, tais como pólen contraído ou vazio são relatados para plantas de pimenta expostas a alta temperatura e seriam responsáveis pelo decréscimo na viabilidade do pólen e, consequentemente, pela baixa produção de sementes (Raja Reddy \& Kakani, 2007).

A alta temperatura observada no telado, na época da coleta das flores, pode ser um dos fatores responsáveis pela baixa viabilidade do pólen nas linhagens CNPH 3773 e CNPH 3000. Lançada como cultivar BRS Seriema, a linhagem CNPH 3773 apresenta elevado nível de resistência ao Potyvirus Pepper yellow mosaic virus (PepYMV), moderada resistência ao Tospovirus Groundnut ringspot virus (GRSV) e uma boa uniformidade de plantas e frutos.

Embora preliminares, os resultados obtidos refletem claramente, a possibilidade de uso dos parâmetros citogenéticos e a importância dessa avaliação prévia em linhagens de Capsicum spp. A estabilidade meiótica e a produção de gametas viáveis são aspectos diretamente associados à reprodução e manutenção das plantas dessas espécies 


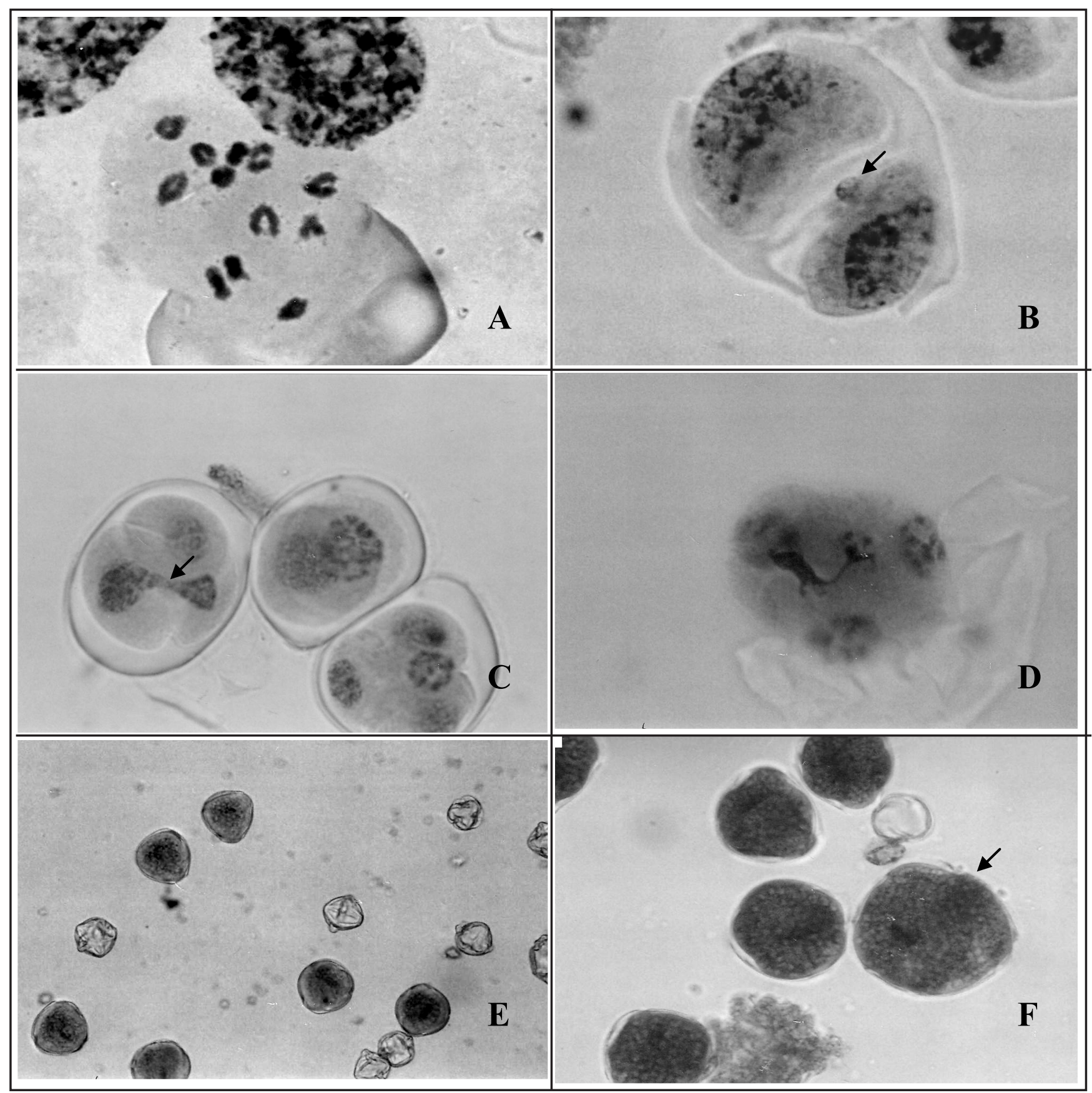

Figura 1. A) Diacinese com 12 bivalentes (diakinesis with 12 bivalents); B) Díade com um micrócito $(\rightarrow)$ (dyad with one microcyte $(\rightarrow)$ ); C) Tétrade com transferência de cromatina entre micrósporos $(\rightarrow)$ (tetrad with chromatin transfer between microspores $(\rightarrow)$ ); D) Aderência em telófase II (stickiness at telophase II); E) Grãos de pólen viáveis (corados) e inviáveis (não corados) (viable (stained) and inviable (notstained) pollen grains); F) Grãos de pólen de diferentes tamanhos, um "gigante" possivelmente gameta não reduzido $(\rightarrow)$ (pollen grains with different sizes, one "giant” possibly unreduced gametes $(\rightarrow)$ ). Brasília, Embrapa Recursos Genéticos e Biotecnologia, 2009.

por meio de sementes. A identificação de genótipos mais estáveis mediante análise citológica permite, portanto, o planejamento de programas de produção de sementes das cultivares em vias de lançamento, como, também, auxilia na eventual utilização destes, para a produção de novas populações.

\section{REFERÊNCIAS}

AULER NMF; BATTISTIN A; REIS MS. 2006. Número de cromossomos, microsporogênese e viabilidade do pólen em populações de carqueja [Baccharis trimera (Less.) DC.] do Rio Grande do Sul e Santa Catarina. Revista Brasileira de Plantas Medicinais 8: 55-63.
BIONE NCP; PAGLIARINI MS; TOLEDO JFF. 2000. Meiotic behavior of several Brazilian soybean varieties. Genetics and Molecular Biology 23: 623-631.

CARVALHO SIC; BIANCHETTI LB. 2008. Botânica e recursos genéticos. In: RIBEIRO CSC; LOPES CA; CARVALHO SIC; HENZ GP; REIFSCHNEIDER FJB (org). Pimentas Capsicum. Brasilia: Embrapa Hortaliças, 2008. p. 39-54. 
GARCIA AG; BATTISTIN A. 2002. Microsporogênese de três espécies do gênero Macroptilium (BENTH.) URBAN (Leguminosae - Papilionoideae) nativas no Rio Grande do Sul. Pesquisa Agropecuária Gaúcha 8: 121-129.

GUERRA M; SOUZA MJ. 2002. Como observar cromossomos: um guia de técnicas em citogenética vegetal, animal e humana. Ribeirão Preto: FUNPEC-Editora.131p.

KAFIZADEHN; CARAPETIAN J; KALANTARI KM. 2008. Effects of heat stress on pollen viability and pollen tube growth in pepper. Research Journal of Biological Sciences 3: 1159-1162.

KUMAR P; SINGHAL VK. 2008. Cytology of Caltha palustris L. (Ranunculaceae) from cold regions of Western Himalayas. Cytologia 73: 137-143.

KUMAR P; SINGHAL VK; KAUR D; KAUR S. 2010. Cytomixis and associated meiotic abnormalities affecting pollen fertility in Clematis orientalis. Biologia Plantarum 54: 181-184.

LOVE RM. 1949. Estudos citológicos preliminares de trigos rio-grandenses. Porto Alegre: Secretaria do Estado dos Negócios da Agricultura, Indústria e Comércio. 23p.

LAKSHMI N; PRAKASH NS; HARINI I; RAMA RAOY. 1989. A case of spontaneous cytomixis coupled with desynapsis in Capsicum annuum L. Cytologia 54: 287-291.

MIRCOVA V; SOTIROVA V. 1995. Cytological investigation on pepper plants infected by Tobacco Mosaic Virus (TMV) in different stages of development. Capsicum and Eggplant Newsletter 14: 54-55.

PAGLIARINI MS. 2000. Meiotic behavior of economically important plant species: the relationship between fertility and male sterility.
Genetics and Molecular Biology 23: 997-1002.

PAGLIARINI MS; FREITAS PM; BATISTA LAR. 2000. Chromosome stickiness in meiosis of a Brazilian Paspalum accession. Cytologia 65: 289-294.

PALMA-SILVA C; PAGGI GM; FELICETTI RA; FERRAZ R; KALTCHUK-SANTOS E; BERED F; BODANESE-ZANETTINI MH. 2008. Meiotic behavior and pollen viability of wild populations of the neotropical species Vriesea gigantea (Bromeliaceae). Plant Species Biology 23: 217-221.

POZZOBON MT; SCHIFINO-WITTMANN MT. 2006. A meiotic study of the wild and semi-domesticated Brazilian species of genus Capsicum L. (Solanaceae). Cytologia 71: 275-287.

RAJA REDDY K; KAKANI VG. 2007. Screening Capsicum species of different origins for high temperature tolerance by in vitro pollen germination and pollen tube length. Scientia Horticulturae 112: 130-135.

RAMSEY J; SCHEMSKE DW. 1998. Pathways, mechanisms, and rates of polyploidy formation in flowering plants. Annual Review Ecology and Systematics 29: 467-501.

REIFSCHNEIDER FJB. (org). 2000. Capsicum: Pimenta e Pimentões no Brasil. Brasília: EMBRAPA Comunicação para Transferência de Tecnologia/Embrapa Hortaliças. 113p.

RIBEIRO CSC; REIFSCHNEIDER FJB. 2008. Genética e melhoramento. In: RIBEIRO CSC; LOPES CA; CARVALHO SIC; HENZ GP; REIFSCHNEIDER FJB (org). Pimentas Capsicum. Brasilia: Embrapa Hortaliças, 2008. p. 55-69.

RISSO-PASCOTTO C; PAGLIARINI MS; VALLE CB. 2009. Chromosome number and microsporogenesis of two accessions of Brachiaria dura Stapf
(Poaceae). Biota Neotropica 9: 257-261. Disponível em: http://www.biotaneotropica. org.br/v9n2/en/abstract? shortcommunication+bn00709022009. Acessado em 08 de setembro de 2010.

SHEIDAI M; PARSIAN H; VAEZI-JOZE S; NOORMOHAMMADI Z. 2008. Chromosome pairing and chiasma formation in some olive (Olea europaea L.) cultivars of Iran. Cytologia 73: 269-274.

SHOPOVA M. 1966. Studies in the genus Capsicum. II. Irregularities in the pollen mother cells. Chromosoma 19: 349-356.

SINGH RJ. 2002. Plant Cytogenetics. Boca Raton: CRC Press. $488 \mathrm{p}$.

SINGHAL VK; KUMAR P. 2008. Impact of cytomixis on meiosis, pollen viability and pollen size in wild populations of Himalayan poppy (Meconopsis aculeata Royle). Journal of Biosciences 33: 371-380.

SINGHAL VK; KAUR D; KUMAR P 2008 Effect of cytomixis on the pollen size in 'Seabuckthorn' (Hippophae rhamnoides L., Elaeagnaceae). Cytologia 73: 167-172.

TASCHETTO OM; PINTRO JC; PAGLIARINI MS. 2003. Chromosome stickiness during microsporogenesis in Pfaffia glomerata and P. tuberosa (Amaranthaceae). The Nucleus 46: 128-137.

TEDESCO SB. 2000. Morfologia, microsporogênese e modo de reprodução das espécies Brasileiras do gênero Adesmia DC. (Leguminosae). Porto Alegre: UFRGS. 163p (Tese doutorado).

ZANOTTO M; BRAMMER SP; NASCIMENTO JUNIOR A; SCAGLIUSI SM. 2009. Viabilidade polínica como seleção assistida no programa de melhoramento genético de triticale. Ciência e Agrotecnologia 33: 20782082. 